\section{Bioethics and genetic research in psychiatry*}

\author{
ANNE E. FARMER, MICHAEL J. OWEN and PETER McGUFFIN
}

In a previous editorial, we wrote optimistically about a "genomics revolution" in psychiatry, and expressed the view that discovering the genetic basis for mental disorders would "enhance diagnostic accuracy, improve treatment and radically alter clinical practice" (Farmer \& Owen, 1996). We speculated that the first impact of such research might be the development of presymptomatic testing for Alzheimer's disease, followed by similar tests for schizophrenia and bipolar disorder. However, we cautioned that where genes of small effect are concerned, predictive value is likely to be low. We also rehearsed some of the complex ethical considerations that would be raised should such tests become available.

Three years on, the rapid pace of technological development in genetic research continues. The most dramatic of these has been mammalian cloning (Wilmut et al, 1997), while new disciplines such as pharmacogenomics and bioinformatics are assuming increasing importance (Tanne, 1998). However, along with optimism about the promise of the new treatments has come a fear that advances in genetics might lead to a 'new eugenics', in which the technology to detect and correct 'disease' genes and their effects could be used on individuals with genes for characteristics and susceptibilities considered 'undesirable' (Harper, 1997). This has highlighted the need for ethical guidelines for genetic research relating to mental disorders, which has recently been recognised in a report from the Nuffield Council on Bioethics (1998). We will therefore consider our earlier predictions in the light of current progress, and

*Declaration of interest. The authors are all active in genetic research and are members of the International Society for Psychiatric Genetics, of which P.McG. is currently president and M.J.O. is a board member. P.McG. was also a member of the working party responsible for the Nuffield Council report, but the views expressed in this editorial are entirely those of its authors. review some of the recent recommendations regarding the ethics of psychiatric genetic research.

\section{THE CURRENT 'STATE OF PLAY' IN THE GENETICS OF MAJOR PSYCHIATRIC DISORDERS}

\section{Type A and Type B polygenic disorders}

We have argued elsewhere that the genetic aetiology of most major psychiatric disorders is most likely to be polygenic and multifactorial (Farmer \& Owen, 1996). Along with other common illnesses such as coronary artery disease, hypertension and diabetes, polygenic mental disorders can be divided into two main types. In the first (Type A), a few rare families have forms of the disorder showing simple Mendelian patterns of transmission that are due to the inheritance of single genetic mutations which are sufficient to cause disease. Such sub-forms are tractable to molecular genetic approaches, and the identification of disease genes can provide important pointers to the aetiology and pathophysiology of more common, polygenic varieties of the disorder. Recent success in finding genes for autosomal dominant, early-onset forms of Alzheimer's disease has opened up new avenues of research into the neurobiology of common forms of the disorder (Goate et al, 1991).

The majority of major mental illnesses, however, are more likely to be Type B disorders, in which rare Mendelian sub-forms are not found. Hence the detection of genes, which for Type B disorders will have small effect, is more difficult and requires analysis of much larger samples, using a combination of allele sharing linkage methods and allelic association studies (Owen \& Craddock, 1996). To date, a number of replicated chromosomal regions of interest have been found for some mental disorders, and some genes of quite small effect have been identified, but much work is still required (Williams et al, 1997). It has been pointed out (DeLisi $\&$ Crow, 1999) that there have been many claims of linkage but little replication across studies. There has also been a lack of agreement between systematic genome searches on any one locus for a phenotype - for example, whether the positive linkage is associated with schizophrenia or bipolar disorder.

In those with Type B and in the majority of those with Type A disorders, disease probably reflects the action of a number of genes, which combine together in an additive and/or multiplicative fashion to give a vulnerability to develop the disorder when other non-genetic risk factors are also present. Such genes are termed susceptibility genes and individually their presence does not mean that the carrier will inevitably develop the illness (McGuffin et al, 1994). In fact, in many instances the predictive value of tests for such genes will be low, as is exemplified by apolipoprotein $\mathrm{E}$ testing for late-onset Alzheimer's disease (Relkin et al, 1996). Indeed, even when all susceptibility genes for a given disorder have been identified, it will still not be possible to predict the development of disease with certainty until the relevant environmental risk factors have also been identified and the nature of the various interactions understood (Owen \& McGuffin, 1997).

\section{The Nuffield Council on Bioethics Report}

For this reason, the Nuffield Council report (Nuffield Council on Bioethics, 1998) concluded that genetic tests would not be useful for diagnosing mental disorder with complex causes either prenatally or in population screening. One of the report's main recommendations was that genetic testing for susceptibility genes which offer low predictive or diagnostic certainty should be discouraged unless there are clear medical benefits. This and other aspects of the report are worth considering in an international context as well as in the context of human genetics generally.

\section{BIOETHICS AND THE PRACTICALITIES OF GENETIC RESEARCH}

\section{Funding for ethics research}

In 1988, the Noble laureate James Watson, then Director of the National Institutes of Health Genetic Research Program, stated 
that he would allocate $3 \%$ of the genetic research budget for research into the ethical, legal and social implications of genetic research (Watson, 1997). The budget for such research then increased annually, and by 1996 had reached US\$7 000000 Elsewhere, funding has been less generous, but a national bioethics committee has existed in France since 1983 (Butler, 1997), and a similar body was more recently established in Germany (Abbott, 1997). The areas that are of most practical relevance are: those relating to informed consent; in the USA the Institutional Review Boards that assess the ethical issues associated with individual research applications (equivalent to local ethics committees in the UK); the role of the individual, their families and confidentiality; and commercial interests in genetic research (Meslin, 1997).

\section{Informed consent}

As in other types of research, participants in genetic research need to understand the likely benefits, foreseeable risks and alternatives to participation. Little physical harm is likely. The usual requirements are the completion of various standardised interviews and psychometric tests, and providing a sample of DNA. For this, even a blood test can often be avoided, because DNA can now be obtained from buccal mucosa cells swabbed or washed from the inside of the cheek.

However, the main ethical concern is that of non-physical harm. Research subjects may fail to understand the difference between testing that is done as part of clinical treatment or diagnosis and that being done for research. Relatives may believe that in agreeing to participate that they will learn more about their own risk for developing a disorder. As we have already outlined, the presence of susceptibility genes does not alone confer the certainty that a disorder will develop, and individual risk assessment is currently not possible. Consent forms must therefore make this explicit, and state that the only benefits will be those of furthering scientific and medical knowledge.

The Nuffield Council on Bioethics Report (1998) also asserts that freely given informed consent guidelines are required for the establishment and maintenance of genetic registers (as a safeguard against new eugenic pressures). The report comments that individuals with mental disorders have capacity (as legally defined) to give informed and genuine consent to participate in research, unless it can be shown otherwise. This emphasises the point that, for the most part, those with mental disorders are not any different in their capacity to understand and agree to participate in research from those with other medical illnesses.

\section{Ethics committees}

The scrutiny of all research proposals involving human subjects by an ethics committee is accepted in most industrialised countries. The guiding principles are those included in the Nuremberg Code (Faraone et al, 1997), which states that research subjects should give voluntary consent, and not be subjected to suffering, and that the research will lead to "fruitful results for the good of society, unprocurable by other methods or means of study". Hence, the code implies that to be considered ethical, the research must also be scientifically sound. In our view, one of the particular problems for local committees in a rapidly advancing field such as genetics is their competence to judge the scientific merits of the proposal. Where a new technological advance or a novel methodological approach is being employed, the committee may have to seek an external opinion; but where research has already been peer reviewed by a funding body, further detailed scrutiny of the scientific merit of the proposal is probably unnecessary.

A second problem relating to the fact that ethics committees are locally based is that genetic research now requires very large samples that may need to be derived from wide geographical areas. Researchers may therefore have to apply to several ethics committees for approval. The situation can arise in which a study given ethical approval in one district is refused it in the adjacent district. To overcome this problem (which also applies to other areas such as clinical trials) the Medical Research Council and other funding bodies in the UK are establishing mechanisms of review by ethics committees with a wider geographical brief.

\section{The role of individuals, their families and confidentiality}

Genetic research often requires information from non-affected family members who need to be approached regarding their participation. How this approach is made has caused some differences of opinion between ethics committees. Clearly, relatives should not be approached if the index subject refuses permission. However, when permission has been given, should the relatives be approached directly by the research team or only via the proband? If the research team is only allowed to contact the relatives through the proband, it can make the research much more difficult, timeconsuming and expensive.

Another ethical issue relating to the inclusion of non-affected family members in genetic research is that the family's perception of the illness may be changed by their involvement in the study. For example, family members may not be aware that an illness is partly caused by faulty genes until the approach to participate in the research is made. There is also the issue of confidentiality: some patients would not wish their relatives to know that they have a mental illness. Family members also sometimes reveal symptoms to a researcher that they have not revealed to anyone else. In such cases the confidentiality of the respondent must be strictly preserved.

\section{Commercialisation of products}

Commercial interest in genetic material has rapidly increased recently. Genes such as the cystic fibrosis gene and the breast cancer 1 gene have been patented in the USA, where the law allows this. A patent has also been granted to the discoverers of one of the mutations in the amyloid precursor protein gene associated with early-onset Alzheimer's disease (Goate et al, 1991). There are two main ethical issues relating to such patenting. The first is whether it is ethical to patent a naturally occurring, biological compound that is not an invention. Although it can be argued that as much time and research effort goes into discovering a DNA sequence as into an invention, the question then arises as to who should receive resulting profits - just the researcher, or also the individuals who provided the DNA.

The issue of ownership of DNA is especially pertinent to a number of ethnic groups and geographically isolated communities who have been approached to provide DNA because they may be genetically informative (see, e.g., 'Aborigines fear gene study may threaten rights'-Sydney Morning Herald, 24 July 1997). In Iceland the government has recently passed legislation allowing a commercial company, deCODE Genetics, access to all medical and genealogical material as well as stored DNA samples for the whole population of the country (approximately 270000 individuals) (Gulcher \& Stefansson, 1998; Berger, 1999). From a genetic perspective Iceland is particularly 
attractive because the population is relatively homogeneous and mainly descended from a small number of founders who arrived a little over 1000 years ago. This makes it a much better hunting ground for genes associated with common diseases than countries with older, more genetically intermixed populations. There has been much criticism about such an enterprise, both within Iceland and abroad. Much of this criticism has centred on concerns regarding invasion of privacy, but there has also been a sort of 'gut reaction' by some to the notion that a commercial enterprise can effectively stage a takeover of an entire nation's DNA. Against this, the parliament of Iceland - a country with limited natural resources - has taken a hard-nosed commercial decision, which it believes will bring financial benefits to its people. In the longer term, deCODE and its major backer, a pharmaceutical giant, aim to identify genes that can inform the search for targets for novel drug development. Undoubtedly, profit is an important motive, but it is difficult to argue that discovery of better, more specific treatments for common disorders is disreputable.

\section{USES AND ABUSES OF BIOETHICS}

Concern has been expressed in recent editorials published in both the Lancet (1997) and Nature (Wadman et al, 1997) regarding the development of a 'bioethics industry'. It has been suggested that the ethical debate is in danger of being taken over by those whose main concern is their own academic and/ or financial advancement rather than the public good. It has also been suggested that such vested interests might be imposing too many constraints on genetic research. Given public sensitivity to psychiatric issues, genetic research in this area could become a particular focus (Marshall, 1998; Michels, 1999).

Ethical issues have been paid considerable attention by the psychiatric genetics research community, and have been the subject of plenary sessions at the most recent world congresses organised by the International Society of Psychiatric Genetics. At the fifth such world congress (held in Santa Fe in 1997), the Director of the ethical, legal and social implications programme, expressed the view that genetic research in psychiatry, with its history of public stigma, should not be allowed to proceed 'unbridled'
(Meslin, 1997). Taking up this equine metaphor in the same session, one of us pointed out that a bridle allows the rider to steer a horse in the right direction, but if too restrictive may cause the horse either not to move or to bolt dangerously (further details available from the first author upon request). Other speakers at that plenary session concentrated on past abuses of psychiatric genetics, particularly in Nazi Germany, and we have discussed this in greater detail elsewhere (Farmer \& McGuffin, 1999). We would argue that despite worries to the contrary and the baggage of its history, psychiatry should not be treated differently from any other branch of medicine with respect to genetic research. To do so is a form of discrimination against those who suffer from psychiatric disorders, and could possibly prevent the benefits deriving from genetic research, which we and others have predicted will be important, from taking place (Farmer \& Owen, 1996; Rutter \& Plomin, 1997).

The Nuffield Council report largely took a similar, if slightly more cautious, approach. It is also worth pointing out that, anecdotally, the effect of genetic findings has been to reduce rather than increase stigma. Examples include the reaction of parents whose offspring suffer from disorders such as schizophrenia or autism to the news that these conditions have a substantial genetic basis and are not a consequence of poor parenting. A more public example is the willingness of famous individuals, such as a past president of the USA, to admit to suffering from the early stages of Alzheimer's disease, something that would have been unthinkable before the advent of modern molecular research, when the popular label would have been 'going senile'.

We are therefore more sanguine about the usefulness of a vigorous and developing bioethics community than are the authors of the recent Lancet and Nature commentaries. We see debates at specialist conferences and reports such as that produced by the Nuffield Council as essential concomitants of the growing field of psychiatric genetics.

Finally, we will touch on the thorny issue of whether ethical values are relative or rooted in a timeless morality. We suspect that in addition to a necessary influence of ethics on scientific practice, there is likely to be a gradual, almost imperceptible influence of scientific knowledge on what is widely accepted as ethical. For example, major advances such as organ transplantation and in vitro fertilisation were controversial in their day but are now regarded as commonplace. We would not be surprised if the outlook on mammalian or even human cloning went in the same direction. Against this background, discussions of the ethical implications of advances in psychiatric genetics are best regarded as something that should be public and open, and not just the reserve of scientists or moral philosophers. Moreover, as long as scientific advances continue we should not expect the debate to reach a final conclusion. Hence, the Nuffield Council report must be welcomed as a major instalment but not the last word on the subject.

\section{REFERENCES}

Abbott, A. (1997) Germany's past still casts a long shadow. Nature, $\mathbf{3 8 9}, 647$.

Berger, A. (1999) Private company wins right to Icelandic gene database. British Medical Journal, 318, II.

Butler, D. (1997) France reaps benefits and costs of going by the book. Nature, 389, 661-662.

DeLisi, L. \& Crow, T. (1999) Chromosome workshops 1998: current state of psychiatric linkage. American Journal of Medical Genetics, 88, 215-219.

Faraone, S.V., Gottesman, I. I. \& Tsuang, M.T. (1997)

Fifty years of the Nuremberg Code: a time for retrospection and introspection. American Journal of Medical Genetics, 74, 345-357.

Farmer, A. \& Owen, M. J. (1996) Genomics: the next psychiatric revolution? British Journal of Psychiatry, 169, 135-138.

— \& McGuffin, P. (1999) Ethics and psychiatric genetics. In Ethics and Psychiatry (3rd edn) (ed. S. Block). Oxford: Oxford University Press.

Goate, A., Chartier-Harlin, M., Mullan, M., et a (1991) Segregation of a missense mutation in the amyloid precursor protein gene with familial Alzheimer's disease. Nature, 349, 704-706.

Gulcher, J. \& Stefansson, K. (1998) Population genomics. Laying the groundwork for genetic disease modelling and targeting. Clinical Chemistry and Laboratory Medicine, 36, 523-527.

Harper, P. (1997) Huntington's disease and the abuse of genetics. In Genetics, Society and Clinical Practice (eds P. Harper \& A. Clarke), pp. 227-228. London: Bios Scientific Publications.

Lancet (1997) The ethics industry. Lancet, 350, 897.

Marshall, E. (1998) Panel tightens rules on mental disorders. Science, 282, 1617.

McGuffin, P., Owen, M. J., O'Donovan, M. C., et al (1994) Seminars in Psychiatric Genetics. London: Gaskell.

Meslin, E. M. (1997) Ethical, legal and social implications of research in psychiatric genetics: thoughts from the ELSI research program at the US National Human Genome Research Institute. American Journal of Medical Genetics, 74, 6 
Michels, R. (1999) Are research ethics bad for our mental health? New England Journal of Medicine, 340 1427-1430.

Nuffield Council on Bioethics (1998) Mental Disorders and Genetics: The Ethical Context. London: Nuffield Council on Bioethics.

Owen, M. J. \& Craddock, N. (1996) Modern molecular genetic approaches to complex traits. Implications for psychiatric disease. Molecular Psychiatry, I, 21-26.

— \& McGuffin, P. (1997) Genetics and psychiatry. British Journal of Psychiatry, I7I, 201-202.

Relkin, N. R., Tanzi, R., Breitner, J., et al (1996)

Consensus statement: apolipoprotein E genotyping in Alzheimer's disease. Lancet, 347, 1091-1095.

Rutter, M. \& Plomin, R. (1997) Opportunities fo psychiatry from genetic findings. British Journal of Psychiatry, I7I, 209-219.

ANNE E. FARMER, FRCPsych, Social, Developmental and Genetic Psychiatric Research Centre, Institute of Psychiatry, London; MICHAEL J. OWEN, FRCPsych, Department of Psychiatry, University of Wales, College of Medicine, Cardiff; PETER McGUFFIN, FRCPsych, Social, Developmental and Genetic Psychiatric Research

Centre, Institute of Psychiatry, London

Correspondence: Professor Anne Farmer, Institute of Psychiatry, De Crespigny Park, London SE5 8AF

(First received 26 January 1999, final revision 17 June 1999, accepted 17 June 1999)

Tanne, J. H. (1998) The new word in designer drugs. British Medical Journal, 316, 1930.

Wadman, M., Levitin, C., Abbott, A., et al (1997) Business booms for guides to biology's moral maze. Nature, 389, 658-659.

Watson, J. D. (1997) Genes and politics. Journal of Molecular Medicine, 75, 624-636.
Williams, J., McGuffin, P., Nothen, M., et al (1997) A meta-analysis of the association between the $5-\mathrm{HT}_{2}$ a receptor $\mathrm{TI} 02 \mathrm{C}$ polymorphism and schizophrenia. Lancet, 349, 1221

Wilmut, T., Schnieke, A. K., McWhir, J., et al (1997) Viable offspring derived from foetal and adult mammalian cells. Nature, 385, 810-813. 